\title{
Las necesidades de formación continua de las personas graduadas de la carrera de Orientación de la Universidad de Costa Rica y el apoyo que puede brindar la gestión educativa
}

\author{
Continuing Education - A Need among Licensed Guidance Counselors Supported by \\ Educational Management
}

Recibido 29 enero 2014 • Aceptado 11 marzo 2014 • Corregido 02 mayo 2014

Grettel Valenciano Canet $^{1}$
Universidad de Costa Rica
Facultad de Educación
Escuela de Orientación y Educación Especial
San José, Costa Rica
grettel.valenciano@ucr.ac.cr

Resumen. En este artículo se sintetizan los resultados de una investigación cuantitativa de tipo descriptivo, cuyo objetivo es detectar las necesidades de formación continua que tienen las personas graduadas de la carrera en Ciencias de la Educación con énfasis en Orientación de la Universidad de Costa Rica, grado licenciatura, en los últimos cinco años y que ejercen la disciplina. Este estudio resultó relevante en la medida que, desde el ámbito de la disciplina de la Orientación, se propone dar respuesta mediante la formación constante a las necesidades de desarrollo profesional requeridas por la sociedad actual. Se evidencian los requerimientos de empleo que demanda la profesión de la Orientación; los fenómenos sociales detectados desde la experiencia profesional en esta disciplina y que requieren una intervención desde esta; así como las necesidades de desarrollo profesional, lo que permite identificar ejes y temáticas de interés de las personas profesionales graduadas en esta disciplina. Además, se considera el apoyo que puedan brindar las personas profesionales a cargo de la gestión educativa en estas organizaciones.

Palabras clave. Formación continua; exigencias del empleo en Orientación; desarrollo profesional; autoafirmación profesional y gestión educativa

Abstract. This article summarizes the results of a descriptive, quantitative study which addrees continuing education needs of persons who have graduated from the University of Costa Rica Education program with a major in guidance counseling in the last five years, and who are currently employed in the field. The study's relevance lies in its assertion that the professional development expected by society from guidance counselors can be achieved through continuing education. Employment requirements in the field are discussed, as are the social issues addressed by guidance counselors, and the professional development requirements they must fulfill. The study identifies basic themes and topics of interest for graduates in this field. In addition it considered the support that can be provided by the education manager.

Máster en Psicopedagogía, Universidad Estatal a Distancia. Licenciada en Psicopedagogía, Universidad Nacional, Bachiller en Ciencias de la Educación con énfasis en Orientación, Universidad de Costa Rica. Profesora de la Escuela de Orientación y Educación Especial, Universidad de Costa Rica. 
Keywords. Continuing education; guidance counseling employment requirements; professional development; professional self-affirmation; educational manager

\section{INTRODUCCIÓN}

Es de interés primordial en este artículo, hacer consciencia en las gestoras y los gestores de la educación, empresas empleadoras y en las personas graduadas de la carrera de Orientación, sobre la importancia de la formación continua.

En el año 2007, la Escuela de Orientación y Educación Especial de la Universidad de Costa Rica, sede Rodrigo Facio, se sometió por primera vez, ante el Sistema Nacional de Acreditación de la Educación Superior (SINAES), al proceso de autoevaluación de las carreras de Ciencias de la Educación con énfasis en Orientación y Educación Especial.

Partiendo específicamente del análisis del Informe de autoevaluación del Bachillerato y Licenciatura en Orientación (2011), se reconoce las necesidades que tienen las personas graduadas de mantenerse actualizadas y recibir formación continua en áreas y temas de interés.

De aquí, la importancia de este estudio para atender las demandas de formación continua por parte de las personas profesionales de la Orientación, actualmente en ejercicio. Ante ello, la gestora y el gestor de los centros educativos o empresas empleadoras de esta disciplina deben estar anuentes a que su personal profesional reciba formación persistente para dar respuesta a las necesidades y demandas de la población, a la vez brindar oportunidades de desarrollo profesional.

Siendo el éxito educativo uno de los principales roles de la gestión de la educación, tal y como lo expone Castillero, Díaz, Morales y Pino de Ochoa (2009), sus esfuerzos también deben orientarse a generar las condiciones y espacios para que los programas de formación continua sean un eje estratégico dentro de la planificación institucional.

En el trabajo de investigación se plantearon los siguientes objetivos específicos:

- Identificar los requerimientos del empleo en Orientación según el criterio de las personas graduadas de esta carrera en la Universidad de Costa Rica en los últimos cinco años y que trabajan actualmente.

- Identificar fenómenos sociales que puedan ser atendidos desde la disciplina de la Orientación según el criterio de las personas graduadas de la carrera de Orientación de la Universidad de Costa Rica en los últimos cinco años y que trabajan en este momento.

- Establecer necesidades de desarrollo profesional según el criterio de las personas graduadas de la carrera de Orientación de la Universidad de Costa Rica en los últimos cinco años y que trabajan actualmente.

Licencia Creative Commons 
Rev. Gestión de la Educación, Vol. 4, N² 2, [1-29], ISSN: 2215-2288, julio-diciembre, 2014

DOI: http://dx.doi.org/10.15517/rge.v4i2.15143

URL: http://revistas.ucr.ac.cr/index.php/gestedu

\section{REFERENTE TEÓRICO}

\section{Formación continua y desarrollo profesional en la disciplina de la Orientación}

En la actualidad, se hace necesaria la formación de profesionales competentes y comprometidos con el desarrollo social de nuestro país. Es por ello, que la formación continua de las personas profesionales de la disciplina de la Orientación constituye un aspecto imprescindible para cualquier sistema educativo o institución que pretenda alcanzar un nivel de excelencia por medio de la renovación constante.

Ahora bien, como marco referencial para ofrecer formación continua a las profesionales y los profesionales de la Orientación, se hace necesaria la definición de este concepto.

En algunos estudios se hace referencia a la actualización y a la formación continua; la primera, según Herdonza (s.f.), en el caso de personas que laboran en educación es la acción "de ponerse al día, estar al tanto de los progresos del conocimiento que intervienen en el proceso educativo y de los nuevos procesos que lo facilitan y lo hacen posible" (p. 31). En el caso de las personas profesionales de la Orientación, independientemente del ámbito laboral, implica estar al día con los nuevos conocimientos que intervienen en los procesos de esta disciplina, entre otros.

El proceso de actualización, de acuerdo con Calderón, Cruz, Leiva, Morales y Solano (2010), se inscribe en el de formación continua y permanente. En este estudio, la actualización estará contenida en la educación continua y este último concepto, a su vez, se entiende como sinónimo de formación permanente.

Por su parte, Imbernón (1994b) hace referencia al concepto y terminología de educación permanente a lo largo del tiempo, indicando que los términos más utilizados son: educación permanente, formación permanente, formación continua, la formación continua profesional, entre otros. El término que se emplee se desprende de los modelos y estrategias que se utilicen.

En esta investigación se emplea el término de formación continua; lo que se busca es el desarrollo profesional de las orientadoras y orientadores en su papel de personas trabajadoras. Por otro lado, Álvarez y Romero (2007) señalan que:

La formación continua de cualquier tipo de profesional tiende a basarse en la adquisición de nuevas competencias que una determinada organización necesita para la consecución de sus objetivos estratégicos: aumentar la competitividad, conseguir nuevos mercados, prestar servicios innovadores demandados por los usuarios o cliente. (p. 23)

Si bien es cierto que las universidades juegan un papel protagónico en la formación continua de las personas profesionales, también les corresponde a estas contribuir, a partir de su experiencia laboral, con la definición de ejes temáticos que deben ser atendidos y a su vez,

\begin{tabular}{|c|c|c|c|}
\hline (i) & $\begin{array}{l}\text { Licencia Creative Commons } \\
\text { Atribución-No-Comercial SinDerivadas } \\
\text { 3.0 Costa Rica. }\end{array}$ & & \\
\hline & Grettel Valenciano Canet & Número publicado el 1 de julio del 2014 & 3 \\
\hline
\end{tabular}


que den respuesta a las necesidades sociales y de formación continua que se detecten. Además, debe existir un compromiso con este tipo de formación.

Cabe mencionar que, cuando se señala la formación continua para las personas profesionales de la Orientación, se pretende que esta sea el camino apropiado para alcanzar las competencias requeridas por el mercado laboral y a la vez, influir en su desarrollo profesional y personal, debido a que pueden autoafirmarse, motivarse y actualizar sus conocimientos. Así, la formación continua de las orientadoras y los orientadores forma parte de los grandes retos actuales para las universidades.

Un perfil profesional al cual se accede por motivación intrínseca y sobre el que hay un alto nivel de exigencia de su contexto profesional y sociocultural, es lógico que reconozca que la formación continua es necesaria. Para Cobos (2010) "está generalizado entre las profesionales y los profesionales de la Orientación que la formación continua es una necesidad inherente al perfil profesional" (p. 675).

Es así, como la persona profesional de la Orientación forma parte del personal de un centro educativo, una empresa u otro tipo de institución y, en varias ocasiones, se verá obligada a tomar decisiones para las cuales necesita estar actualizada. Además, la demanda surge de la práctica cotidiana de la disciplina de la Orientación. Por otra parte, García (1999) menciona que:

La educación y la formación, de forma cada vez más creciente, serán los principales vehículos para la concienciación, integración, el avance y el desarrollo personal; la educación adquirida en el sistema formal, en el trabajo o de una forma más informal, es la clave para contratar el propio futuro y el desarrollo. (p. 63)

Sin duda, los procesos de formación continua dan como producto el desarrollo profesional y social.

Es importante para este estudio, destacar los tres aspectos que propone Mata (2011) para ser considerados en el momento de determinar acciones de educación continua; a saber: las necesidades sociales, las exigencias del empleo y las condiciones en que transita la persona a lo largo de su desarrollo profesional. Estos tres elementos se consideran claves en esta investigación.

\section{Desarrollo profesional en Orientación}

Es importante considerar que uno de los principales objetivos de la formación continua es el fortalecimiento del desarrollo personal y de la motivación, en este caso, de las personas profesionales de la disciplina de la Orientación.

Se hace necesario, como marco referencial para mejorar la capacidad de desempeño laboral de las profesionales y los profesionales de la Orientación, hacer referencia al concepto de desarrollo profesional. De acuerdo con Imbernón (1994a) este concepto engloba los procesos

Licencia Creative Commons

Atribución-No-Comercial SinDerivadas (cc) (†) 3.0 Costa Rica. 
que mejoran el conocimiento profesional, las habilidades y las actitudes, en particular de las personas profesionales de la Orientación.

El desarrollo profesional se presenta como un proceso continuo; difícilmente se pueden definir períodos claros y diferenciados por los que transcurre este desarrollo, según el autor mencionado anteriormente, se han propuesto tres fases:

- Una fase de formación básica o inicial y socialización profesional, caracterizada por la formación inicial profesional en instituciones de Educación Superior.

- Una fase de inducción profesional y socialización de la práctica que se ubica al menos en los tres primeros años de ejercicio profesional, ya sea en una institución educativa u otro ámbito laboral.

- Una fase de perfeccionamiento en la que predominan las actividades de formación permanente, desarrolladas como parte del sistema en el cual se labora o inducidas por la misma persona profesional en Orientación.

En el contexto costarricense, la primera fase responde a la formación universitaria recibida según la elección vocacional de la persona y una segunda etapa caracterizada por la transición de la universidad al mundo de trabajo y consecuentemente los primeros años de ejercicio profesional. La tercera etapa, la de perfeccionamiento. (Vargas, 2008, p. 15)

La formación de las personas profesionales de la Orientación es, por lo tanto, un proceso continuo y de larga duración que no se agota durante la etapa de la formación inicial. Así, la profesión de Orientación se encuentra permanentemente demandada por los cambios y avances que se operan en los diferentes contextos de la sociedad, la cultura, la política, las tecnologías y el conocimiento científico.

El desarrollo profesional de las personas que trabajan en Orientación constituye, por ende, una estrategia fundamental para renovar su profesión y responder a las nuevas necesidades de la sociedad costarricense.

Por otro lado, Ferreres e Imbernón (1999) afirman que "el desarrollo profesional del profesorado se realiza no únicamente en la acumulación de créditos de formación, sino en el contacto día a día con el resto de condiciones sociales, laborales y ambientales, más allá de la estructura formativa" (p. 27).

Desde el punto de vista de los autores mencionados, se concibe la formación como desarrollo profesional, en este caso de las orientadoras y los orientadores, directamente en relación con el proceso de mejora de las funciones que desempeñan como profesionales de esta disciplina. Desde esta perspectiva, según las funciones a desarrollar por las personas profesionales de la Orientación, se entenderá de una forma u otra su desarrollo profesional.

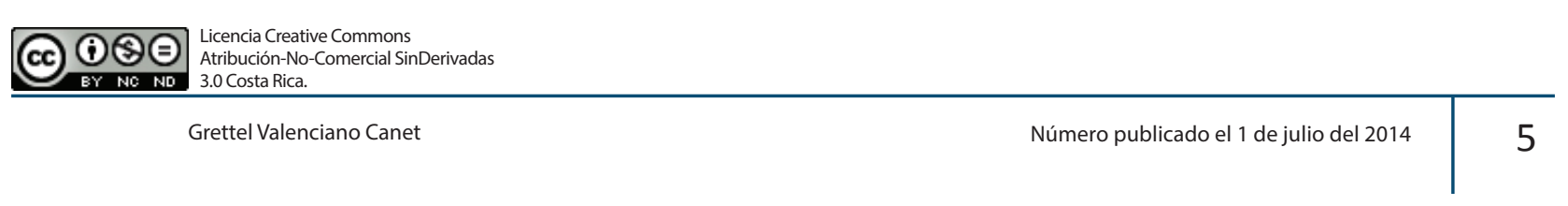


Para Mata (2007), la formación para el desarrollo profesional incide en el mejoramiento de la práctica orientadora y profesional en general, pues amplía las posibilidades de autoafirmación profesional. Esta última es un elemento que permanece constantemente a lo largo de este proceso de desarrollo profesional.

La autoafirmación, de acuerdo con De Mézerville (2004), es entendida como la libertad de la persona de ser ella misma y tomar decisiones para conducirse con autonomía y madurez. Es la capacidad de manifestarse abiertamente a la hora de expresar sus pensamientos, deseos o habilidades y está directamente relacionada con la autodirección y la asertividad personal. En relación con lo anterior, Mata (2003) considera que:

Aplicado el concepto de autoafirmación al desarrollo profesional, se puede definir la autoafirmación profesional como la capacidad desarrollada mediante la formación y el ejercicio laboral, para actuar con autonomía y madurez mediante la toma de decisiones, en busca de soluciones pertinentes a los problemas que enfrenta la persona trabajadora profesional. (pp. 6-7)

Desde esta perspectiva, según la autora mencionada, una persona profesional que se aprecie tiende a defender su necesidad básica de manifestarse como es, de proponer e implementar soluciones, de aportar al mejoramiento de su colectividad haciendo uso de su experiencia profesional y de aportar de manera innovadora.

Por estas razones, a través de la educación continua, la persona profesional en Orientación puede desarrollar su habilidad de autoafirmación profesional, incidiendo en el mejoramiento de su práctica profesional, su desarrollo personal y social. Así mismo, el proceso de desarrollo profesional debe ser una respuesta a los retos que le plantea el ambiente laboral.

\section{Requerimientos de empleo en la disciplina de la Orientación}

Cabe señalar que, en este estudio, los requerimientos de empleo se refieren a los conocimientos, habilidades, actitudes y condiciones necesarias para desempeñarse competentemente en el puesto que ocupa como profesional de la disciplina de la Orientación. (Barboza y Gutiérrez, 2005; Escuela de Orientación y Educación Especial, 2000).

Un reto importante para la disciplina de la Orientación es poder anticipar e identificar las nuevas competencias profesionales que las futuras instituciones o empresas empleadoras requerirán de estos profesionales, con el fin de adaptar la formación continua de las personas profesionales a sus necesidades.

La formación continua debe orientarse, en última instancia, al desarrollo de competencias profesionales que capaciten a las personas graduadas de la disciplina, teniendo en cuenta,

Licencia Creative Commons
Atribución-No-Comercial SinDerivadas (C) $\$$ 3.0 Costa Rica. 
según Bonals y Sánchez (2007) "que las competencias requieren de conocimientos y habilidades de distinta índole y estrategias para movilizarlos en la resolución de las situaciones" (p. 95).

Por otra parte, las ofertas de formación continua dirigidas a las personas profesionales de la Orientación tienen que considerar una exigencia mayor, la cual supere una simple oferta de cursos con temáticas variadas. Esto se constituye en un reto y compromiso para las entidades que brinden una formación continua basada en el desarrollo de competencias para estos profesionales. Exige a las instituciones de educación superior una tarea continuada de investigación y respuesta a las demandas sociales y profesionales.

Ser una persona profesional competente, según Álvarez y Romero (2007), "en definitiva, implica, estar dotada no sólo de conocimientos teóricos y técnicos, sino también de habilidades, destrezas y actitudes que faciliten desenvolverse socialmente y participar activamente en el contexto en que se desarrolla la profesión" (p. 18).

En esta línea, es importante mencionar que deben existir ajustes entre la formación de la persona profesional de la disciplina de la Orientación y el contexto laboral en el cual se desenvuelve, debido a que en este se encuentran las auténticas necesidades que la sociedad y el mercado laboral le demandan. Motivo por el cual, es fundamental poder ofrecer programas de educación continua que den soluciones al empleo de las personas graduadas en esta disciplina.

Todo lo anterior, frente a la importancia que las personas empleadoras puedan darle a la cualificación profesional de la orientadora y del orientador. Referida esta última "a las capacidades profesionales que se poseen y, en definitiva, a la competencia profesional" (Pérez y Blasco, 2003, p. 191). En otras palabras "la capacidad de desempeñar las tareas inherentes a una ocupación determinada" (Pérez y Blasco, 2003, p. 202). Es así como:

El trabajo y la formación profesional constituyen un binomio inseparable que debe ser considerado no solo a la hora de formular la educación inicial o formal, la cual por su naturaleza es más difícil transformar o actualizar, sino sobre todo la oferta de educación continua por su naturaleza flexible y oportuna puede dar respuestas inmediatas y situadas en el campo laboral. (Mata, 2011, p. 3)

En conclusión, para mantener la calidad de la educación de las personas profesionales de la Orientación y de las instituciones o empresas donde laboran se hace necesaria, entonces, la formación continua como un esfuerzo por mejorar la capacidad de desempeño laboral y profesional, siempre desde los principios de prevención y desarrollo humano, tomando en cuenta además, las condiciones ambientales y contextos en los que se desenvuelven las personas.

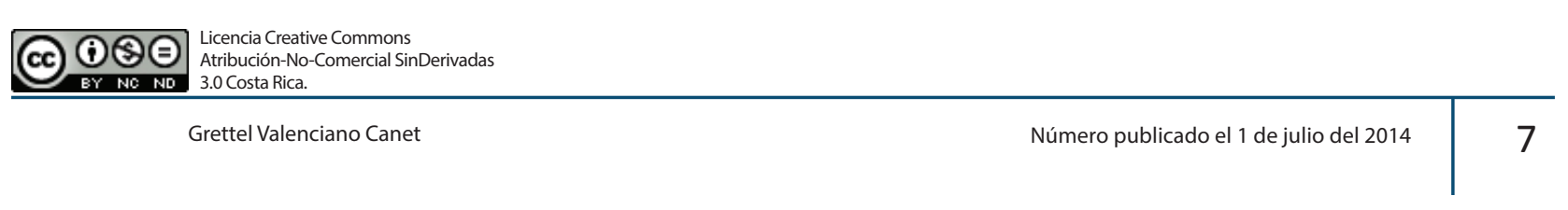




\section{La Orientación como alternativa para enfrentar los fenómenos sociales}

La Orientación como práctica social debe responder, desde los ámbitos de su competencia, a los fenómenos sociales. Sin embargo, definir y caracterizar el fenómeno social no es una tarea fácil; a continuación, se hace necesaria una conceptuación del mismo.

El fenómeno social es un suceso que resulta de una sociedad alterada y que tiene como consecuencia el desequilibrio de esta. Para Uzcategui (1990) también puede considerarse como la actitud consciente de la persona ante los fenómenos de la vida social y su propia condición social que la impulsa, de manera inevitable, a un cambio social.

Se consideran como fenómenos sociales la drogadicción, la violencia, la delincuencia, el consumismo y otros. Siguiendo con este concepto, Mata (2011) plantea que "el fenómeno social es complejo y multifacético por lo que su caracterización resulta difícil. No obstante es indispensable para la articulación de propuestas de educación continua en tanto que el trabajo constituye la fuerza dinámica que lo conforma" (p. 4). Para esta autora, existen indicadores que retratan las condiciones sociales imperantes y de las cuales es posible identificar necesidades sociales. La actuación en Orientación, según Álvarez y Romero (2007):

Se desarrolla en un contexto de calidad, es decir, parte de la detección de necesidades sociales y educativas y, a partir de ahí, se elabora un plan de acción coherente, fomentando la innovación y el cambio. Esta actuación debe estar sometida a procesos de evaluación continua. (p. 19)

Por último, puede decirse que la sociedad actual demanda, cada vez, nuevos retos para la persona profesional de la Orientación, quien como agente de cambio debe ser capaz de identificar aquellas necesidades sociales que puedan ser abordadas desde esta disciplina. Y es a través de la formación continua que buscará la transformación personal, organizacional y social.

\section{Las personas profesionales de la Orientación en Costa Rica}

En nuestro país se presentan una serie de acontecimientos que determinan el inicio de la disciplina de la Orientación en el sistema educativo formal. Según la Escuela de Orientación y Educación Especial (2000), en el Plan de Estudios de la carrera de Orientación:

La Orientación existe en Costa Rica como disciplina aplicada de las Ciencias de la Educación, porque se han dado ciertas condiciones históricas, socioeconómicas, políticas y culturales, que han hecho sentir la necesidad de ofrecer a la población estudiantil fundamentalmente, una atención especializada a sus necesidades de Orientación personal, educacional y vocacional. (p. 7)

La necesidad de la Orientación es reconocida expresamente en la Ley Fundamental de Educación, aprobada en el año 1957, en el artículo 22. En Costa Rica, la Orientación como práctica

Licencia Creative Commons

Atribución-No-Comercial SinDerivadas (cc) (†) 3.0 Costa Rica. 
Rev. Gestión de la Educación, Vol. 4, N² 2, [1-29], ISSN: 2215-2288, julio-diciembre, 2014

DOI: http://dx.doi.org/10.15517/rge.v4i2.15143

URL: http://revistas.ucr.ac.cr/index.php/gestedu

profesional se inició en los colegios de segunda enseñanza, en el año de 1964. Sin embargo, no fue sino hasta el año 1971 que se ofreció un plan de estudio en la Universidad de Costa Rica para otorgar el grado de Bachillerato y Licenciatura en Ciencias de la Educación con Énfasis en Orientación.

En los años 1966 y 1967 surgió la Orientación en el Sistema Penitenciario de nuestro país, con la incorporación de las Guías Correccionales para atender las situaciones de convivencia de las personas reclusas de la Penitenciaría Central (Acuña, Carmiol, Elizondo, Salazar y Villalobos, 2012).

A continuación, se considera necesario hacer referencia al concepto de Orientación señalando que:

Es una disciplina de las Ciencias de la Educación, que por sus orígenes, las características que posee de disciplina aplicada y por su objeto de estudio, se nutre de otras disciplinas de las Ciencias Sociales. Su objeto de estudio son los procesos de autoconocimiento, identidad, contexto natural y sociocultural, toma de decisiones y planeamiento para la vida, con la finalidad de ayudar a clarificar y construir el sentido de vida que asumen para su existencia en las diferentes etapas y situaciones vitales. (Escuela de Orientación y Educación Especial, 2000, p. 17)

Actualmente, existen en nuestro país profesionales de la disciplina de la Orientación que laboran en diferentes ámbitos: en los centros de educación preescolar, primaria, secundaria y universitaria. Asimismo en instituciones del Estado, como es el caso del Sistema Penitenciario Nacional, el Instituto sobre Alcoholismo y Farmacodependencia, organizaciones no gubernamentales, consulta privada, empresas privadas, entre otros. Sin embargo, el Ministerio de Educación Pública (MEP) sigue siendo el mayor empleador.

Las funciones que deben desempeñar, en la actualidad, las personas profesionales de la Orientación en el sistema educativo formal, según el Plan de estudios de la carrera de Orientación de la Universidad de Costa Rica, están debidamente reconocidas por el Servicio Civil y por la legislación que rige el MEP. Además, "la formación universitaria recibida, capacita también a las personas profesionales de la Orientación para prestar sus servicios profesionales en otros ámbitos laborales y en la práctica privada" (Escuela de Orientación y Educación Especial, 2000, p. 7).

Las funciones desempeñadas y las áreas de intervención propias de la Orientación en Costa Rica, así como las nuevas funciones y contextos en los que deben ejercerse, hacen necesario en las personas profesionales de esta disciplina, un desarrollo profesional que dé respuesta a las nuevas expectativas. Es por ello que, según Sebastián (2003), "tanto la formación continua como la experiencia deben tender a una amplitud y a la vez especialización" (p. 366).

Como se observa, es por medio de la educación continua que se pretende promover el desarrollo profesional de las orientadoras y los orientadores, a fin de cumplir con las exigencias del empleo y responder, al mismo tiempo, a las necesidades sociales.

\begin{tabular}{|c|c|c|c|}
\hline (c) $\bigcirc \$(-)$ & $\begin{array}{l}\text { Licencia Creative Commons } \\
\text { Atribución-No-Comercial SinDerivadas } \\
\text { 3.0 Costa Rica. }\end{array}$ & & \\
\hline & Grettel Valenciano Canet & Número publicado el 1 de julio del 2014 & 9 \\
\hline
\end{tabular}




\section{El apoyo de la gestión educativa en los programas de formación continua}

Tomando en cuenta que el Ministerio de Educación Pública es el mayor empleador de las personas profesionales de la Orientación, es de gran importancia el apoyo que pueda brindar la gestión educativa. Asimismo, la educación como apoyo fundamental de la sociedad costarricense requiere de personas profesionales en el campo de la gestión de la educación, comprometidas de hacerla efectiva, ofreciendo una educación de calidad acorde con las demandas actuales de la sociedad.

La gestión de la educación es un proceso integral coherente y unificado en busca de los logros de los objetivos institucionales planteados, en función de los distintos planes, programas y proyectos, en busca del desarrollo curricular, materiales y humanos (Castillero et al., 2009). De esta forma, los distintos procesos de desarrollo organizacional, como por ejemplo los procesos de formación continua, requieren de adecuados diagnósticos de necesidades y procesos de gestión asumidos mediante un liderazgo trasformador, con el propósito de operacionalizarlos y que sus servicios incidan en el mejoramiento profesional, así como en la población meta a la que van dirigidos.

La gestión de la educación como responsable de velar por la calidad de los distintos servicios educativos que tiene a cargo, requiere apoyarse de acertados procesos de detección de necesidades de formación continua. Los procesos de formación continua, en la actualidad, requieren de constantes procesos evaluativos, debido a los acelerados y desafiantes cambios que una sociedad globalizada como la actual exige, donde es necesario una gestión que sepa responder en forma acertada los distintos cambios a considerar dentro de su planificación institucional, en función de las demandas en las cuales emerge.

La conducción de las organizaciones escolares, tal y como lo expone Pozner, Ravela y Fernández (2000), requieren un acompañamiento de gestión estratégica. Siendo así, es importante establecer espacios y estrategias para el cumplimiento de sus objetivos; se espera desde la gestión, para un adecuado cumplimiento de sus objetivos, una serie de condiciones de viabilidad que permitan plasmar su planificación institucional. De la misma forma y tomando en cuenta las exigencias mundiales, cada vez las organizaciones acuden a programas de formación continua como una herramienta de gestión para mantener actualizados sus profesionales y asegurar servicios de calidad. Dentro de estas condiciones generadas por la gestión de la educación se encuentran:

- Fomentar una cultura evaluativa de las demandas de formación continua.

- Promover el desarrollo profesional, generando espacios y condiciones.

- Establecer procedimientos que permitan detectar en forma acertada las demandas del entorno.

- Ejecutar los procesos de formación continua en forma eficiente de manera que estos procesos se lleven a cabo según los objetivos planteados y según un diagnóstico previo.

Licencia Creative Commons 
- Velar para que los profesionales adquieran las competencias necesarias para su adecuado desempeño profesional.

A pesar de que las organizaciones puedan contar con acertados programas de formación continua, estos logran su ejecución siempre y cuando cuenten con una gestión moderna, transformadora, que oriente a la institución, a los cambios y procesos necesarios según las necesidades detectadas. Una gestión de la educación transformadora es consciente que los programas, para su ejecución, requieren de los recursos humanos y financieros necesarios; de esta forma, planifica, coordina y organiza todos los apoyos con que cuenta para asegurar el éxito de los servicios que ofrece. Machado, citado en Castillero et al. (2009) señala que "para el éxito escolar uno de los roles del gestor o gestora educativa es la preocupación por la capacitación de los docentes con el fin de mejorar su desempeño..." (p. 54).

Es evidente que parte del rol de la gestión educativa es su preocupación y apoyo por la formación continua del personal docente, en este caso en particular de la persona profesional en el campo de la Orientación, visto como un apoyo sustantivo en la proyección futura y como recurso para responder a las demandas que la sociedad requiere actualmente. Es importante el apoyo y acompañamiento, coordinación y comunicación permanente que se brinde a este profesional de Orientación.

\section{PROCEDIMIENTO METODOLÓGICO}

\section{Descripción y sustento del método de investigación utilizado}

Este estudio es abordado desde un enfoque de investigación de tipo cuantitativo, con un alcance descriptivo. La investigación descriptiva comprende, además de la descripción, el registro, análisis e interpretación de los fenómenos, su naturaleza y composición (Tamayo y Tamayo, 2002). Además, este tipo de estudio contribuye a tener un panorama más amplio de las necesidades de formación continua y ayuda a jerarquizar las variables que se asocian con estas necesidades, tales como los requerimientos de empleo, los fenómenos sociales y las necesidades de desarrollo profesional.

Así, para lograr la descripción del fenómeno objeto de estudio, se siguieron los siguientes pasos:

- Idea y planteamiento del problema: del Informe de autoevaluación de la carrera de Bachillerato y Licenciatura en Orientación, realizado por la Escuela de Orientación y Educación Especial (2011), se reconoce la necesidad de actualización y de recibir formación continua de las personas graduadas, en áreas y temas de interés profesional.

- Revisión de la literatura y referente teórico: en este paso se reconoce la importancia de estar al día con los progresos del conocimiento que intervienen en el proceso educativo para aumentar la competitividad y prestar servicios de Orientación. 
- Visualización delalcance de la investigación:seexplora el contexto ocupacional delas personas profesionales en Orientación para describir las necesidades de actualización; los resultados favorecerán el planteamiento de programas de formación continua desde la Escuela de Orientación y Educación Especial de la Universidad de Costa Rica. Las opiniones recolectadas ofrecerán la perspectiva de formación actualizada desde la experiencia de las personas profesionales de la disciplina y servirá como base para el desarrollo de investigaciones o proyectos de acción social posteriores que busquen la ampliación de la temática.

- Diseño de la investigación: con el listado de nombres de personas graduadas facilitado por la Escuela de Orientación y Educación Especial, se procedió a elaborar una base de datos que contenía: número de teléfono, correo electrónico y año de graduación. Una vez filtrada la información, de acuerdo con los criterios de inclusión (graduados en los últimos cinco años), se procedió a efectuar contacto telefónico o por correo electrónico para completar la información: carné, año de ingreso a la UCR, año de ingreso a la carrera, primer apellido, segundo apellido y nombre, año en que obtuvo el título, lugar y datos del trabajo, teléfonos y correo electrónico. Una vez confirmada esta información, se procedió a elaborar un cuestionario en formato digital para aplicar con la herramienta Google docs.

\section{Descripción y sustento de las técnicas utilizadas}

El cuestionario utilizado para la recolección de datos se diseñó de acuerdo con las variables e indicadores planteados para detectar las necesidades de formación continua de la población meta. Este cuestionario contiene preguntas cerradas y abiertas; fue evaluado por personas expertas para determinar la validez de contenido, además de brindar aportes con respecto al formato, redacción de las preguntas y opciones de respuestas, de tal manera que fueran precisas. Revisaron la utilización de lenguaje inclusivo, la relevancia de las preguntas y la adecuación del lenguaje. Las personas expertas son de amplia trayectoria docente de la Escuela de Orientación y Educación Especial. Cabe aclarar que los fenómenos sociales incorporados en el cuestionario fueron identificados en un grupo focal con personas graduadas de la carrera de Orientación, en el marco del proceso de autoevaluación para fines de acreditación de esta carrera.

Para identificar los conocimientos, áreas de formación, habilidades, competencias y actitudes que requieren las personas profesionales de la Orientación, se utilizó el perfil del plan de estudios de la carrera, así como el uso de aquellos perfiles extraídos de los diarios impresos de mayor circulación nacional.

\section{Población a la que va dirigida la investigación}

La población objeto de estudio la constituyen todas las personas graduadas con el grado de Licenciatura de la carrera de Ciencias de la Educación con énfasis en Orientación de la

Licencia Creative Commons

Atribución-No-Comercial SinDerivadas (cc) (†) 3.0 Costa Rica. 
Rev. Gestión de la Educación, Vol. 4, N² 2, [1-29], ISSN: 2215-2288, julio-diciembre, 2014

DOI: http://dx.doi.org/10.15517/rge.v4i2.15143

URL: http://revistas.ucr.ac.cr/index.php/gestedu

Universidad de Costa Rica, en los últimos cinco años (desde 2007 hasta 2011) y que estaban ejerciendo la disciplina en el momento del levantamiento de la información. De acuerdo con el registro digital de la Escuela de Orientación y Educación Especial, la cantidad de personas graduadas con este grado asciende a 105 personas.

\section{Selección de la muestra o personas participantes}

El cuestionario fue aplicado a una muestra voluntaria. Se envió la invitación a todo el listado de personas egresadas que cumplieron con el criterio de inclusión, respondiendo las personas que quisieron hacerlo voluntariamente. Se logró una participación de $65 \%$, correspondiente a 68 personas profesionales en Orientación. Para este tamaño de muestra $(n=68)$, considerando un nivel de confianza de $95 \%$ y un porcentaje estimado de la muestra de $50 \%$ (p), el error estándar es de $\pm 7 \%$.

\section{Descripción del procedimiento seguido para recolectar y analizar los datos}

Se elaboró una base digital con la información descrita anteriormente que contiene los datos de las personas profesionales e incluye los números de teléfono, correo electrónico, lugar donde laboran, entre otros.

Se diseñó un cuestionario con preguntas cerradas y abiertas previamente evaluadas como ya se mencionó, con la finalidad de determinar la validez de contenido. Una vez incorporadas las observaciones y correcciones al cuestionario, se utilizó la herramienta proporcionada por Google docs y se diseñó un formulario que fue enviado, por este mismo medio, a los contactos ingresados.

Una de las ventajas que posee esta herramienta es que crea una matriz de respuestas de manera simultánea al llenado de cada una de las personas participantes. Además del contacto electrónico, se dio seguimiento telefónico para confirmar la recepción satisfactoria del cuestionario y motivar a las personas profesionales en Orientación para que participaran en la investigación, ofreciéndoles una explicación de la importancia de los resultados para el presente estudio.

\section{Forma de análisis de la información}

Con la ayuda del paquete estadístico SPSS se elaboraron los cuadros de frecuencia absoluta y relativa para conocer el perfil de las personas participantes y las respuestas a cada una de las preguntas. Las variables de estudio son: la información académica y laboral, las necesidades de formación continua constituida por tres indicadores (requerimientos del empleo en Orientación, fenómenos sociales y desarrollo profesional).

En el análisis se priorizaron los resultados más sobresalientes, de manera tal que se lograra visualizar una respuesta al problema de investigación. Posteriormente, se hizo una discusión de los resultados obtenidos, con el objetivo de encontrar significados, a la luz de la teoría 
que respalda este proyecto de investigación. Y por último, se elaboraron las conclusiones, permitiendo a la investigadora proponer ejes y temáticas para la formación continua de las personas graduadas en Orientación.

\section{DISCUSIÓN Y ANÁLISIS DE LOS RESULTADOS}

En este apartado se presenta una síntesis del análisis de los datos, a partir de los resultados obtenidos más relevantes, en relación con la información académica y laboral, los requerimientos del empleo en Orientación, los fenómenos sociales detectados desde la experiencia profesional en Orientación que requieren una intervención desde esta disciplina y las necesidades de desarrollo profesional. Cabe aclarar que la interpretación de los resultados de esta investigación se realiza partiendo de las variables e indicadores de este estudio y teniendo como base la luz de la teoría.

\section{Información académica y laboral}

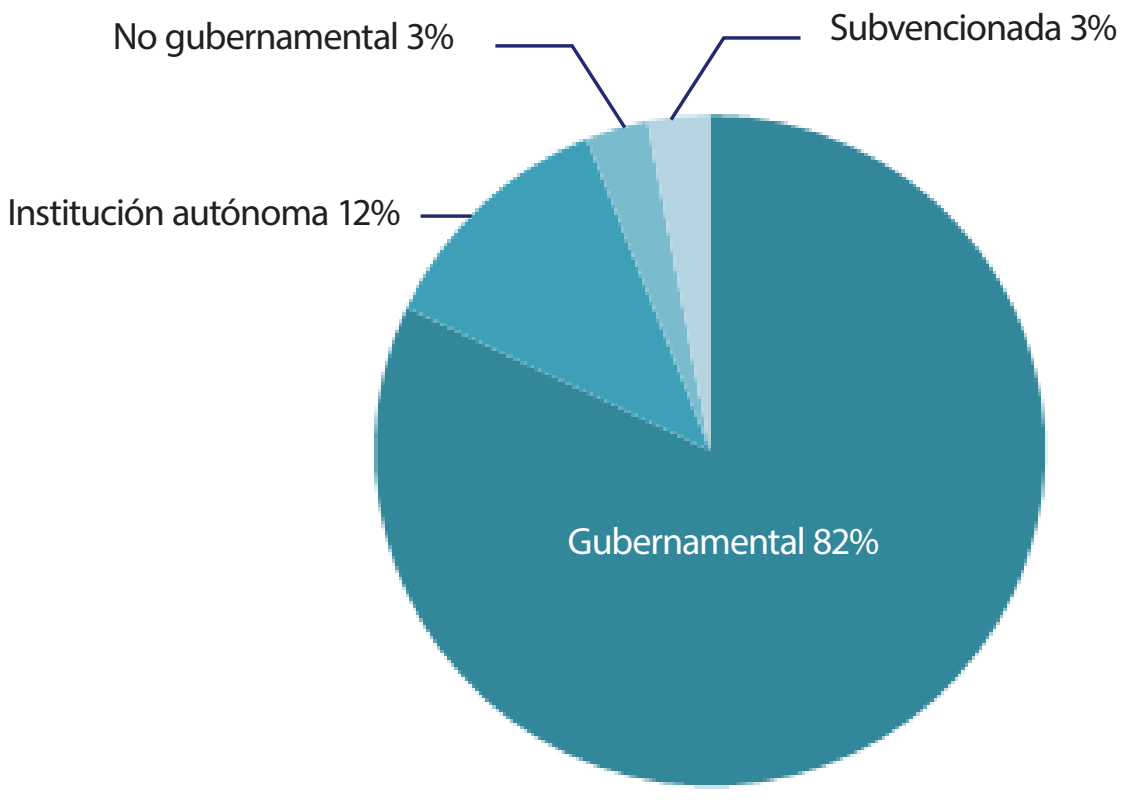

Nota: Cuestionario aplicado a los profesionales en Orientación, 2013.

Figura 1. Tipo de institución donde labora $(\mathrm{N}=68)$ 


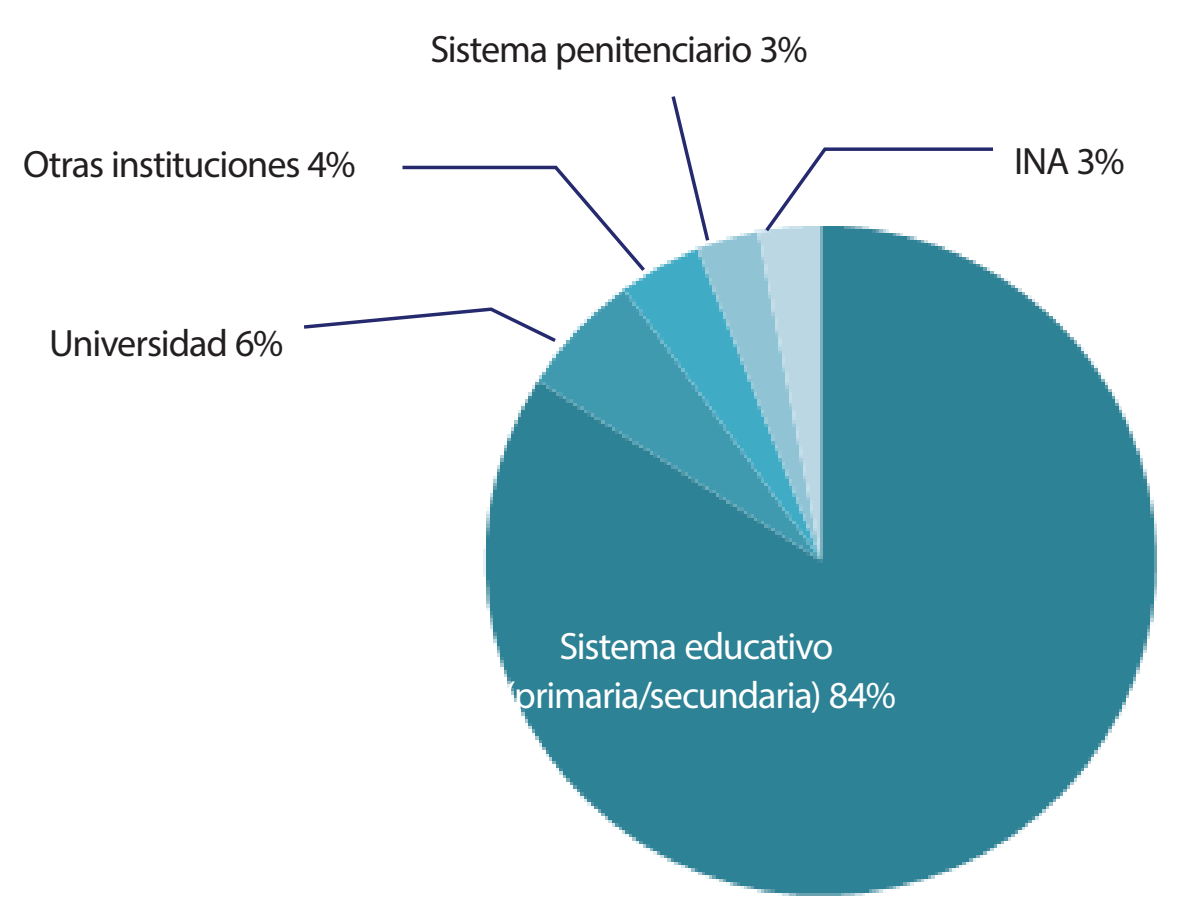

Nota: Cuestionario aplicado a los profesionales en Orientación, 2013.

Figura 2. Institución donde labora la persona profesional $(\mathrm{N}=68)$

En relación con la variable información académica y laboral, la cual se puede apreciar en la Figura 1, el 82\% de la población encuestada labora para el Ministerio de Educación Pública (MEP), siendo que la mayoría se desempeña en educación primaria y secundaria (ver Figura 2). Esta situación obedece a que el Estado es el mayor empleador de las personas profesionales de la Orientación en Costa Rica, al amparo del artículo 22 de la Ley Fundamental de la Educación (1957).

El estudio revela que el $12 \%$ de las personas encuestadas se desempeñan en instituciones autónomas, tales como la Universidad de Costa Rica, el sistema penitenciario, el Instituto Nacional de Aprendizaje (INA) y otras, cuyo marco legal de creación está permeado de alguna manera por el Estado. Un 3\% de las personas encuestadas señala laborar en instituciones subvencionadas, lo que indica que la amplitud de cobertura de empleo en esta disciplina por parte del Estado costarricense es mayor.

No obstante, a pesar de la existencia del marco legal referido, el estudio también revela que un $3 \%$ de la población trabaja en instituciones no gubernamentales. Estas cifras son importantes por cuanto permite saber que el perfil profesional con el que egresa el estudiantado de la carrera 
de la Orientación, le permite desempeñarse en otros ámbitos de educación no formal y por lo tanto, implica que este perfil profesional es congruente con muchas de las competencias que cada ambiente laboral le demanda.

La concentración de instituciones educativas estatales, autónomas, no gubernamentales y otras en el Valle Central promueve, a su vez, la agrupación de profesionales en esta disciplina en las principales provincias del país. El estudio señala que un $43 \%$ de las personas encuestadas laboran en la provincia de San José, seguida de la provincia Cartago con un 35\%. Alajuela ocupa el tercer puesto con un 12\%. La provincia de Limón y Puntarenas, en cambio, con un $4 \%$ y un 3\%, respectivamente.

Llama la atención que la provincia de Heredia sea comparable con provincias periféricas del país, en este caso con un 3\%, dato que no se explica reconociendo en ella tantos centros educativos y servicios. En relación con lo anterior, se encontró que un $76 \%$ de las personas encuestadas se desempeñan en la zona urbana, mientras que el $24 \%$ restante lo hace en la zona rural del país. Este comportamiento concuerda con el hecho de que es en la zona urbana donde se concentran más y mejores servicios, la mayoría de las instituciones educativas, las universidades y otras instituciones, mejores condiciones generales de desarrollo que garantizan en buena medida, llevar una vida cómoda para sus habitantes, convirtiéndose el sector urbano del país en una zona apetecible para muchas personas, desde el punto de vista laboral.

\section{Fenómenos sociales detectados desde la experiencia profesional en Orientación}

La Orientación, como práctica social, debe responder desde los ámbitos de su competencia a los fenómenos sociales. El fenómeno social es un suceso que resulta de una sociedad alterada y que tiene como consecuencia el desequilibrio de esta. Para Uzcategui (1990) también puede considerarse como la actitud consciente de la persona ante los fenómenos de la vida social y su propia condición social, que la impulsa, de manera inevitable, a un cambio social.

En relación con el indicador fenómenos sociales detectados desde la experiencia profesional en Orientación que han venido a transformar la dinámica social y que requieren una intervención desde esta disciplina, se distinguen la violencia como vía para la solución de conflictos, con un $93 \%$ de menciones, seguido del acoso escolar con un $87 \%$ (ver Figura 3). Se señala además, entre los fenómenos sociales que requieren intervención desde la Orientación, al manejo inadecuado de las emociones con un 85\%; continúa la drogadicción con un $81 \%$ y las pocas competencias familiares para enfrentar retos actuales, con un $75 \%$. Las personas profesionales en Orientación que participaron del estudio señalan, con un puntaje alto, a la deserción escolar y a la inadecuada educación de la sexualidad, con un 71\%, respectivamente, como fenómenos sociales que deben ser abordados desde la disciplina.

Licencia Creative Commons 
Rev. Gestión de la Educación, Vol. 4, N² 2, [1-29], ISSN: 2215-2288, julio-diciembre, 2014

DOI: http://dx.doi.org/10.15517/rge.v4i2.15143

URL: http://revistas.ucr.ac.cr/index.php/gestedu

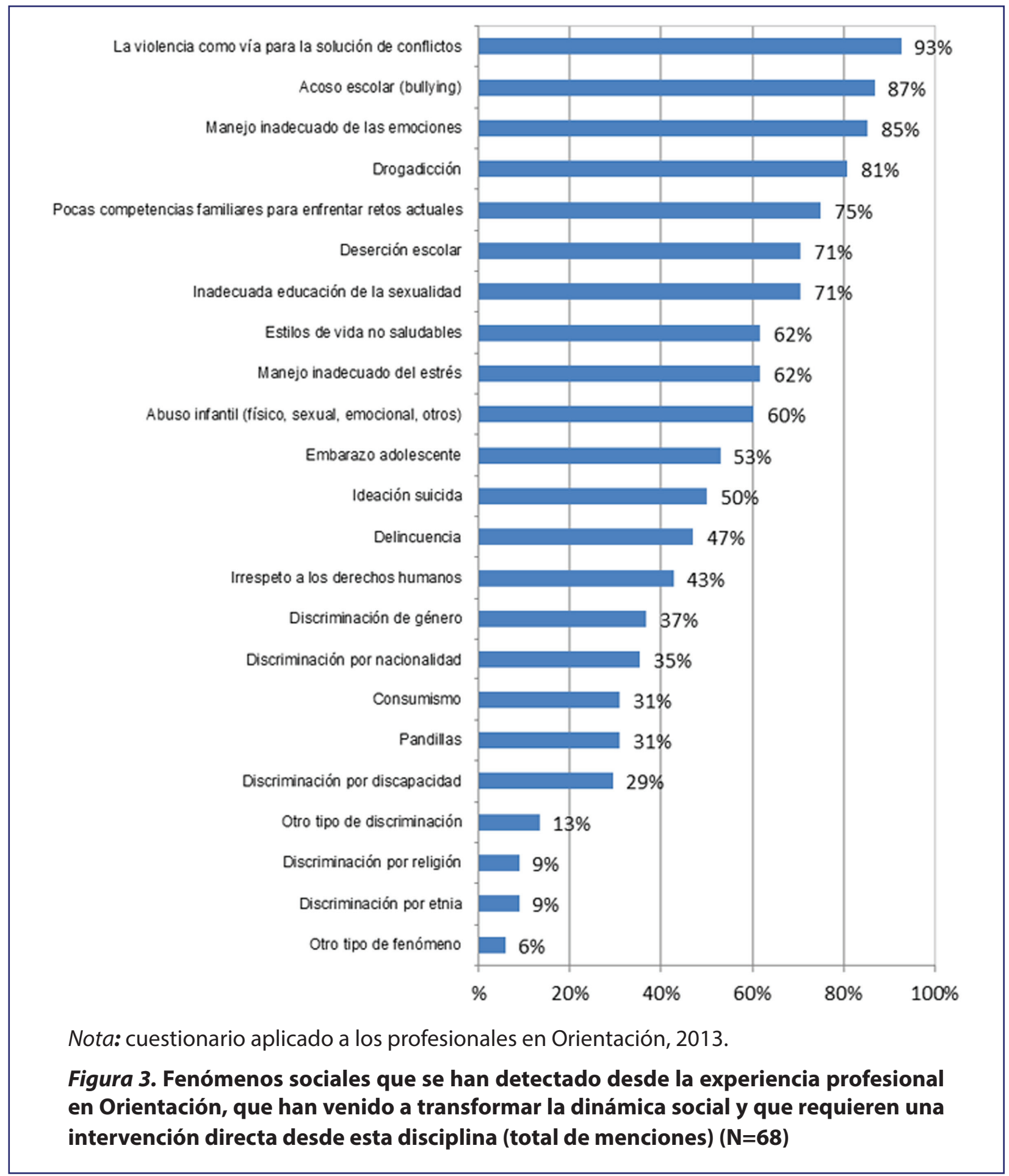




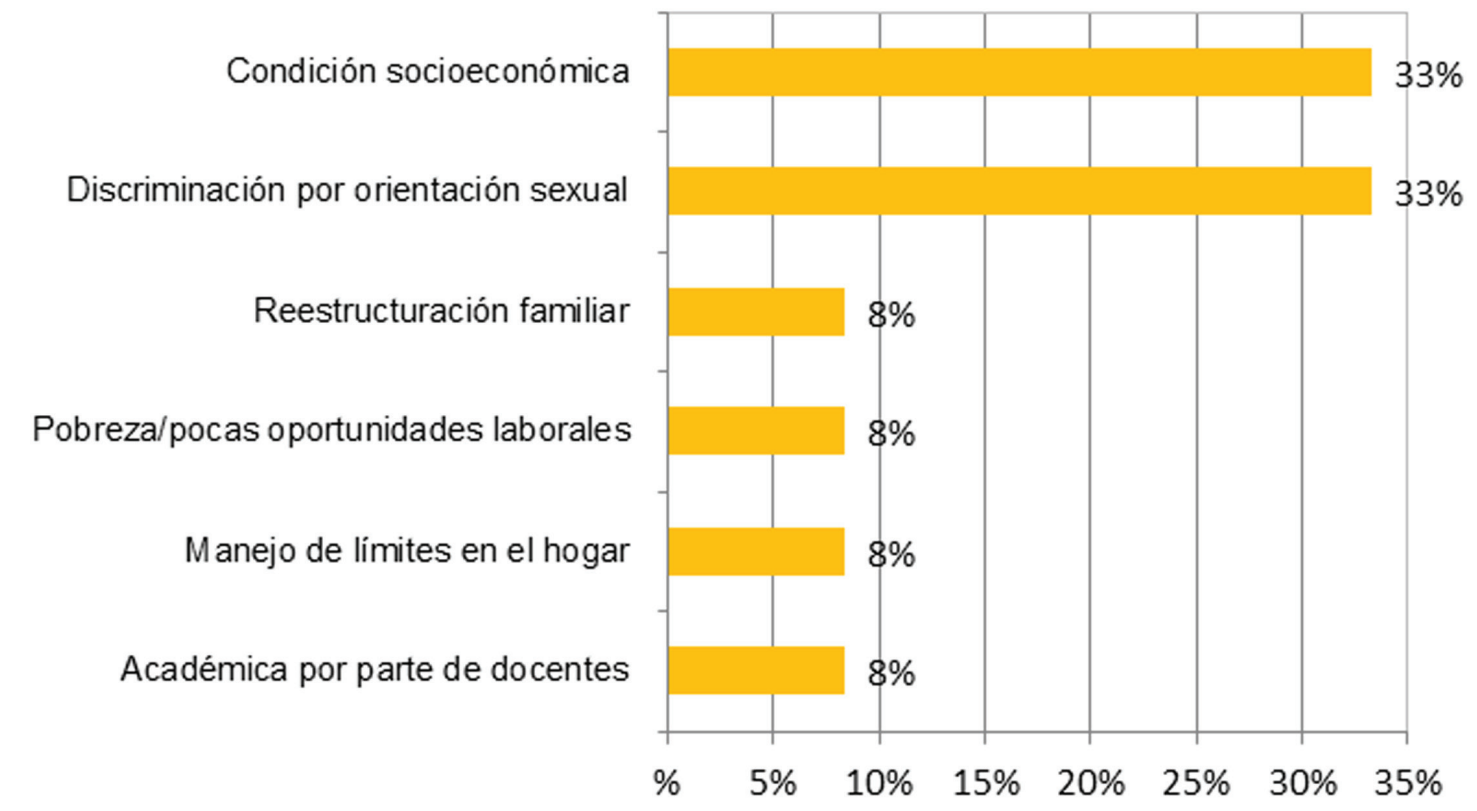

Nota: Cuestionario aplicado a los profesionales en Orientación, 2013.

Figura 4. Otros fenómenos sociales o discriminaciones que requieren ser atendidos desde la disciplina de la Orientación $(\mathrm{N}=12)$

La Figura 4 señala la existencia de otros fenómenos sociales que no se pueden dejar de lado y que requieren ser atendidos desde la disciplina de la Orientación. Estos son: condición socioeconómica y discriminación por orientación sexual; ambos presentan un 33\% de opiniones al respecto.

Se observa también que la reestructuración familiar, la pobreza y pocas oportunidades laborales, el manejo de límites en el hogar y asuntos académicos por parte del personal docente, conforman un segmento del presente estudio que representa un $8 \%$ para cada una de ellas.

La Orientación tiene un marcado carácter social; uno de los propósitos es que la persona se integre dentro de los subsistemas sociales. La disciplina de la Orientación entra en juego en ese proceso de socialización progresiva y se presenta como alternativa para enfrentar los fenómenos sociales. Cabe entonces resaltar la importancia de dar respuesta, desde la disciplina de la Orientación, a estos fenómenos sociales que destruyen o afectan la sociedad costarricense, los cuales deben ser prevenidos e intervenidos desde los ámbitos de competencia de esta profesión.

No cabe duda, que es a través de la formación continua que se buscará la transformación profesional, organizacional y social. Mata (2011) plantea que "el fenómeno social es complejo y multifacético por lo que su caracterización resulta difícil. No obstante es indispensable para la

Licencia Creative Commons Atribución-No-Comercial SinDerivadas (cc) (†) 3.0 Costa Rica. 
Rev. Gestión de la Educación, Vol. 4, N² 2, [1-29], ISSN: 2215-2288, julio-diciembre, 2014

DOI: http://dx.doi.org/10.15517/rge.v4i2.15143

URL: http://revistas.ucr.ac.cr/index.php/gestedu

articulación de propuestas de educación continua en tanto que el trabajo constituye la fuerza dinámica que lo conforma" (p. 4).

Se puede intuir que la sociedad actual demanda, cada vez más, nuevos retos para la persona profesional de la Orientación. Esta como agente de cambio debe ser capaz de identificar aquellas necesidades sociales para ser abordadas.

\section{Necesidades de formación continua}

En relación con la variable necesidades de formación continua, se analiza y desglosa desde tres indicadores: los requerimientos de empleo, los fenómenos sociales detectados desde la experiencia profesional en Orientación y el desarrollo profesional.

\section{Los requerimientos del empleo en Orientación}

La formación de las personas profesionales de la carrera de Orientación, según el plan de estudio de la misma propuesto por la Escuela de Orientación y Educación Especial de la Universidad de Costa Rica (2000), requiere que el estudiantado obtenga el dominio de un conjunto de conocimientos propios de la disciplina de la Orientación y de otras disciplinas de apoyo. Así mismo, se promueve el desarrollo tanto de habilidades básicas (qué debe saber hacer) como de actitudes que, en su conjunto, deben ser aplicadas en la práctica orientadora.

Es necesario señalar que, en este estudio, los requerimientos de empleo se refieren a los conocimientos, habilidades, actitudes y condiciones necesarias para desempeñarse competentemente en el puesto que se ocupa como profesional de la disciplina de la Orientación (Barboza y Gutiérrez, 2005).

Se parte del hecho que las personas profesionales participantes poseen los conocimientos de la disciplina y por ello, se exploran habilidades para el trabajo en equipo; el manejo de grupos; liderazgo; habilidades sociales; elaboración de programas, proyectos o planes; investigación; formulación de asesoramientos dirigidos a distintas poblaciones y contextos; coordinación de trabajos en grupo de naturaleza interdisciplinaria; evaluar programas, proyectos o planes.

Entre las actitudes tenemos las siguientes: disposición para la actualización y formación continua; ser una persona proactiva y con iniciativa; compromiso ético; ser una persona receptiva a las observaciones que se le formulen; apertura y respeto por las diferencias ideológicas y políticas; actitud analítica y crítica; actitud reflexiva permanente en relación con su práctica profesional. Se agrega además, conocimientos de un segundo idioma; manejo de paquetes informáticos y de herramientas tecnológicas novedosas.

Un reto importante para la disciplina de la Orientación es poder anticipar e identificar las nuevas competencias profesionales y los requerimientos de empleo que las instituciones o empresas empleadoras demandarán de estos profesionales en el futuro y ofrecerles, por parte de las universidades del país, una formación continua. 
Ser una persona profesional competente, para Álvarez y Romero (2007), "en definitiva, implica estar dotada no sólo de conocimientos teóricos y técnicos, sino también de habilidades, destrezas y actitudes que faciliten desenvolverse socialmente y participar activamente en el contexto en que se desarrolla la profesión" (p. 18).

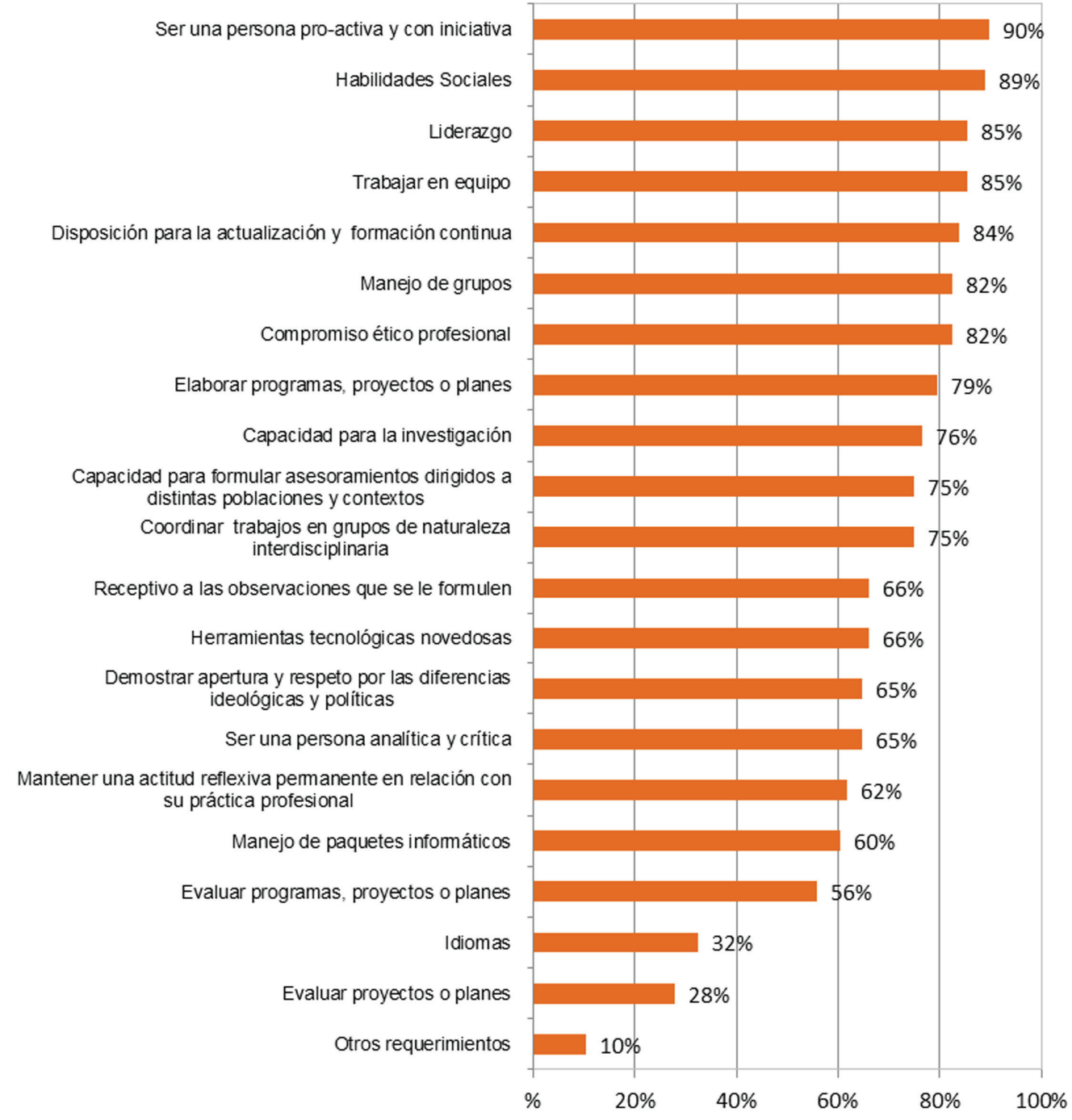

Nota: Cuestionario aplicado a los profesionales en Orientación, 2013.

Figura 5. Requerimientos de empleo que demanda la profesión de Orientación actualmente (total de menciones) $(\mathrm{N}=68)$

Licencia Creative Common 
En relación con el indicador sobre los requerimientos de empleo que demanda actualmente la disciplina de la Orientación, se evidencian, en la Figura 5, los siguientes: encabeza la lista, con un $90 \%$, la actitud de ser una persona proactiva y con iniciativa; seguido de las habilidades sociales con un $89 \%$; el liderazgo y el trabajo en equipo, con un $85 \%$ cada uno. Con un porcentaje ligeramente inferior, el poseer una disposición para la actualización y formación continua, para un 84\%; elaborar programas, proyectos o planes con un 79\%; capacidad para la investigación con un 76\%; capacidad de formular asesoramientos dirigidos a distintas poblaciones y contextos y coordinar trabajos en grupos de naturaleza interdisciplinaria, con un $75 \%$, respectivamente.

Es interesante señalar como un hallazgo que, únicamente el 32\% de las personas profesionales en Orientación señalan el manejo de otro idioma como requerimiento de empleo que demanda esta profesión en la actualidad. Así mismo, solo el $28 \%$ de las personas encuestadas señalan como requerimiento de empleo, la evaluación de proyectos o planes. No obstante los resultados anteriores, el resto de los requerimientos de empleo que demanda la profesión de Orientación actualmente señalados en la figura anterior, del total de menciones, los resultados oscilan entre el $56 \%$ y $82 \%$, denotando la importancia de cada uno de ellos.

Por otra parte, las ofertas de formación continua dirigidas a las personas profesionales de la Orientación exigen, por lo tanto, a las instituciones de educación superior u otras entidades, una tarea continuada de investigación y respuesta a las demandas sociales y profesionales. Es así como:

El trabajo y la formación profesional constituyen un binomio inseparable que debe ser considerado no solo a la hora de formular la educación inicial o formal, la cual por su naturaleza es más difícil transformar o actualizar, sino sobre todo la oferta de educación continua que por su naturaleza flexible y oportuna, puede dar respuestas inmediatas y situadas en el campo laboral. (Mata 2011, p. 3)

Por último, para mantener la calidad de la educación de las personas profesionales de la Orientación y de las instituciones o empresas donde laboran, se hace necesaria entonces la formación continua, como un esfuerzo por mejorar la capacidad de desempeño laboral y profesional. 


\section{Necesidades de desarrollo profesional}

Actividades de actualización / de aprovechamiento

Legislaciones / en educación

Herramientas tecnológicas

Consultas entre profesionales / procesos conjuntos

Educación de la sexualidad

Apertura de posgrados

Nuevas tendencias, aportes teóricos

Trabajo interdisciplinario

Cursos virtuales / materiales en formato digital

Atención individual

Orientación vocacional

Investigación / diagnósticos

Cultura organizacional

Derechos humanos

Administración de proyectos

Redes de apoyo

Cápsulas informativas

Fenómenos sociales que apremian a la disciplina

Fortalecer el curriculo en áreas de prioridad laboral

Patologías psicológicas

Congreso de Orientadores

Psicología de grupos

Comunicación

Idiomas

Técnicas de estudio creativas

Evaluación educativa

Actualización en temas no tradicion Vertical (Category) Axis

Apertura en otros campos de trabajo

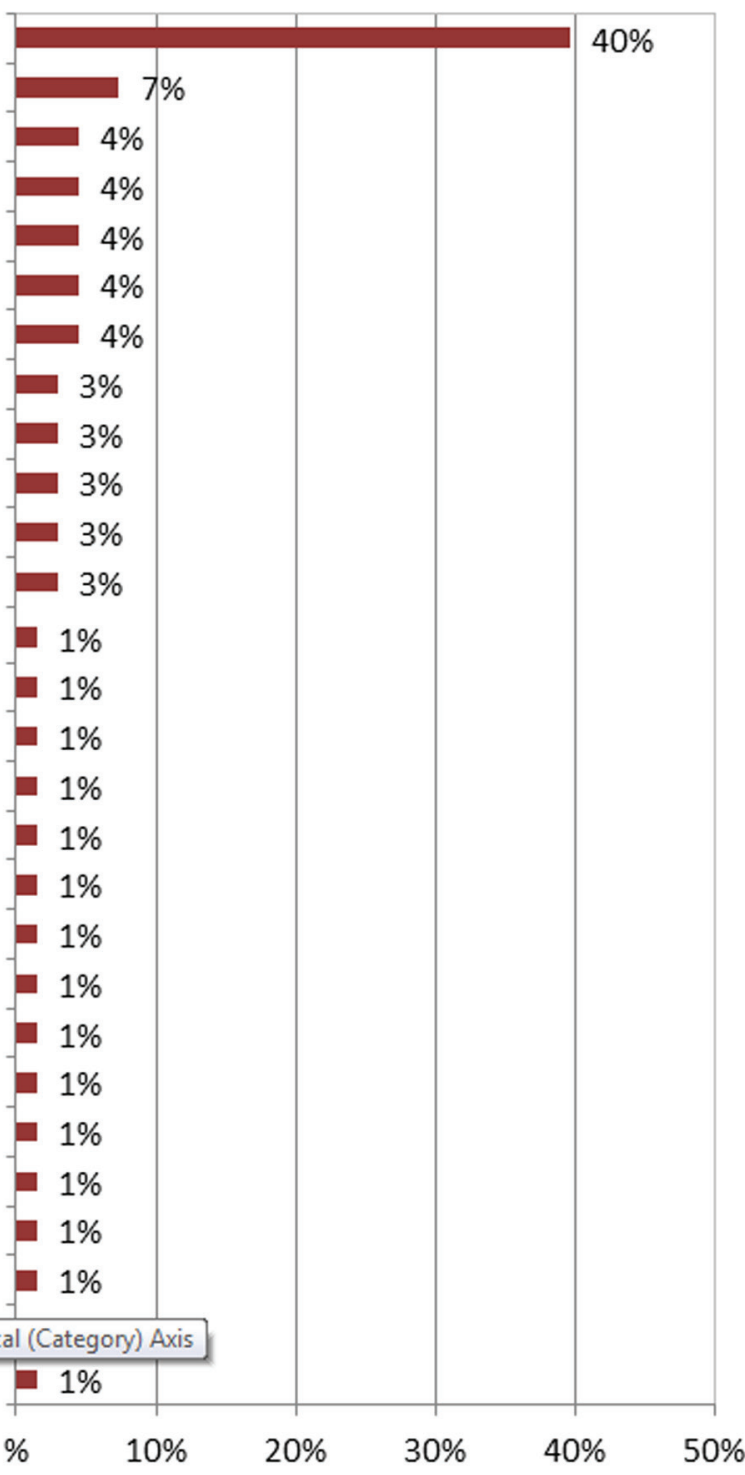

Nota: Cuestionario aplicado a los profesionales en Orientación, 2013.

Figura 6. Acciones formativas que pueden mejorar el desempeño en el trabajo (total de menciones) $(\mathrm{N}=68)$ 
Rev. Gestión de la Educación, Vol. 4, N² 2, [1-29], ISSN: 2215-2288, julio-diciembre, 2014

DOI: http://dx.doi.org/10.15517/rge.v4i2.15143

URL: http://revistas.ucr.ac.cr/index.php/gestedu

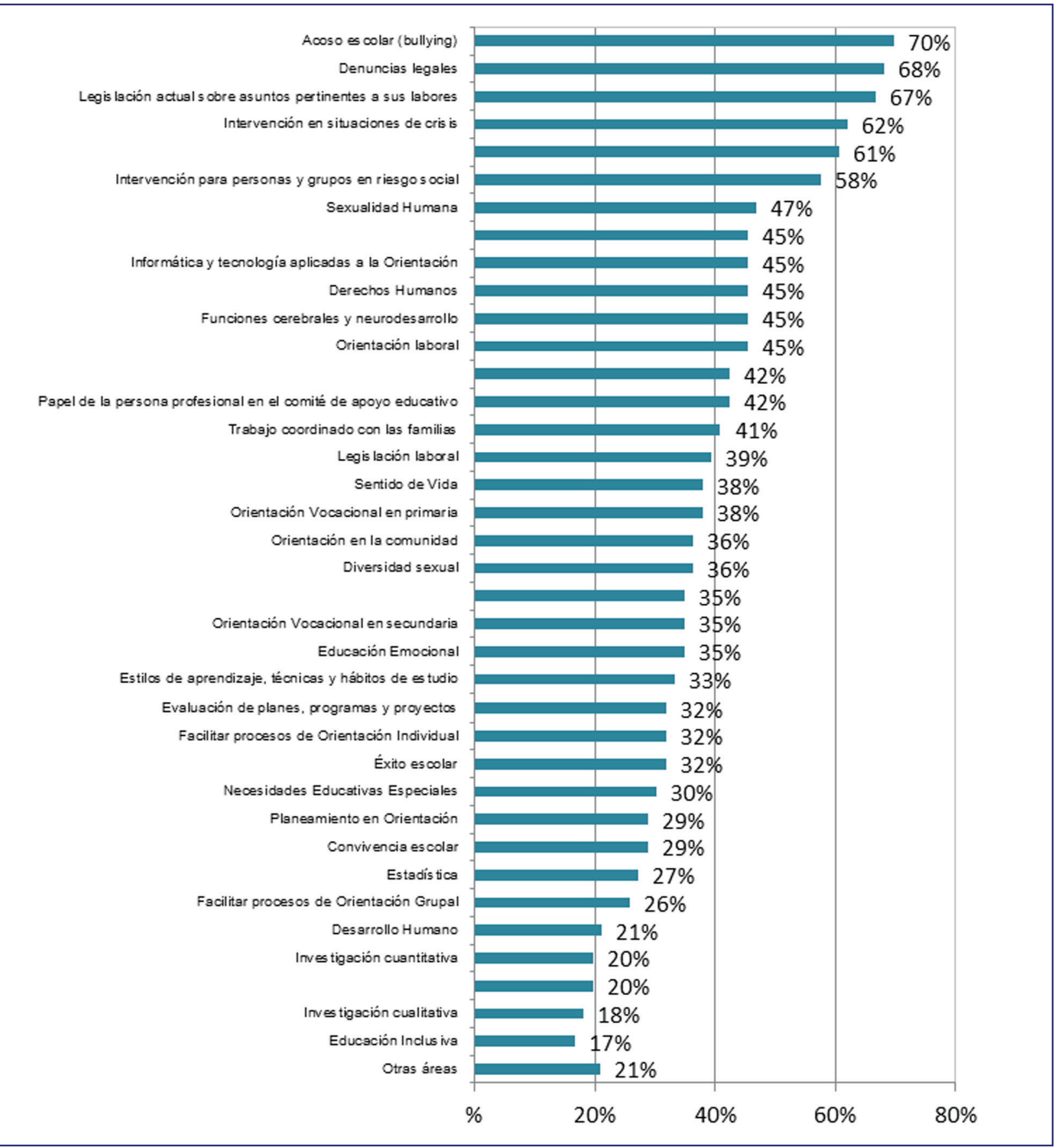

Nota: Cuestionario aplicado a los profesionales en Orientación, 2013.

Figura 7. Áreas que requieren mayor formación para enfrentar las demandas en Orientación (total de menciones) $(\mathrm{N}=68)$ 
Es importante considerar que, uno de los principales objetivos de la formación continua es el fortalecimiento del desarrollo personal y de la motivación, en este caso, de las personas profesionales de la disciplina de la Orientación.

Los hallazgos en relación con el indicador desarrollo profesional que se extraen de la Figura 6 indican que, del total de menciones aportadas por las personas profesionales encuestadas, la acción formativa que puede mejorar el desempeño en el trabajo es la actividad de actualización o de aprovechamiento, con un 40\%. El resto de las acciones formativas que pueden mejorar el desempeño en el trabajo rondan valores de entre el $1 \%$ y el $7 \%$. Se pone de manifiesto la necesidad de ofrecer una formación continua a las personas profesionales que ejercen la profesión.

No obstante, las personas encuestadas consideran necesario recibir cursos de formación continua, una vez terminados los estudios universitarios. Además, señalan su interés de participar en actividades de formación continua en la Universidad de Costa Rica. Como dato importante, el $84 \%$ de las personas profesionales en Orientación sometidas a la encuesta, señala que el horario en el que prefiere recibir formación continua es durante el transcurso del período lectivo.

Sin embargo, es importante señalar como otro de los hallazgos que, solamente el $4 \%$ de las personas encuestadas, indican que un posgrado puede mejorar el desempeño en el trabajo. De acuerdo con Imbernón (1994a) el desarrollo profesional, engloba los procesos que mejoran el conocimiento profesional, las habilidades y las actitudes, en este caso, en particular, de las personas profesionales de la Orientación.

El desarrollo profesional se presenta como un proceso continuo; difícilmente se pueden definir períodos claramente diferenciados por los que transcurre este desarrollo, según el autor mencionado anteriormente, se han propuesto tres fases; es en la tercera donde se ubica la mayoría de la población encuestada: la de perfeccionamiento. En esta predominan las actividades de formación permanente, desarrolladas como parte del sistema en el que se labora o inducidas por la misma persona profesional en Orientación.

La formación de las personas profesionales de la Orientación es, por lo tanto, un proceso continuo y de larga duración que no se agota durante la etapa de la formación inicial. Así, la profesión de Orientación se encuentra permanentemente demandada por los cambios y avances que se operan en los diferentes contextos de la sociedad, la cultura, la política, las tecnologías, el conocimiento científico, entre otros.

En la Figura 7 se aprecia que, del total de menciones, las cinco principales áreas que requieren mayor formación para enfrentar las demandas de la disciplina de la Orientación son las siguientes: acoso escolar (bullying) con un 70\% (este hallazgo de formación en relación con el acoso escolar (bullying) concuerda con el hecho de que este tema aparece dentro de los cinco primeros fenómenos sociales que requieren de una atención prioritaria); seguidamente está las

Licencia Creative Commons Atribución-No-Comercial SinDerivadas (cc) (†) 3.0 Costa Rica. 
Rev. Gestión de la Educación, Vol. 4, N² 2, [1-29], ISSN: 2215-2288, julio-diciembre, 2014

DOI: http://dx.doi.org/10.15517/rge.v4i2.15143

URL: http://revistas.ucr.ac.cr/index.php/gestedu

denuncias legales con un 68\%; la legislación actual sobre asuntos pertinentes a sus labores con un 67\%; la intervención en situaciones de crisis con un 62\% y finalmente, la identificación de los indicadores conductuales de posibles trastornos de personalidad, con un $61 \%$.

Si bien es cierto que la universidad juega un papel protagónico en la formación continua de las personas profesionales, también les corresponde a estos profesionales contribuir, a partir de su experiencia laboral, con la definición de ejes temáticos que deben ser atendidos $y$, al mismo tiempo, den respuesta a las necesidades sociales y de formación continua que se detectan. La formación continua para Álvarez y Romero (2007):

De cualquier tipo de profesional tiende a basarse en la adquisición de nuevas competencias que una determinada organización necesita para la consecución de sus objetivos estratégicos: aumentar la competitividad, conseguir nuevos mercados, prestar servicios innovadores demandados por los usuarios o clientes. (p. 23)

Es importante mencionar que, cuando se señala la formación continua para las personas profesionales de la Orientación, se pretende que esta sea el camino apropiado para se alcancen las competencias requeridas por el mercado laboral y a la vez, influir en su desarrollo profesional y personal, debido a que pueden autoafirmarse, motivarse y actualizar sus conocimientos. Así, la formación continua de las orientadoras y los orientadores forma parte de los grandes retos actuales para las universidades y colegios profesionales del país, lo que requiere de una eficiente gestión de la educación. Siendo el Ministerio de Educación Pública el mayor empleador, es fundamental el apoyo de una gestión educativa eficiente que conduzca a la ejecución de estrategias para tornar dinámico el proceso educativo. Arroyo (2009) indica que la administración pretende, a través de grupos organizados de personas, el cumplimiento y logro de los objetivos y metas definidas, para los cuales se requieren procesos de toma de decisiones importantes que marcan el curso de acción de la organización educativa.

\section{CONCLUSIONES}

Respecto del primer objetivo, el cual pretende identificar los requerimientos del empleo en Orientación, se identificaron en mayores porcentajes los siguientes: ser una persona proactiva y con iniciativa; tener habilidades sociales; liderazgo; saber trabajar en equipo; disposición para la actualización y formación continua; ser capaz de elaborar programas, proyectos o planes, así como para investigar. La persona profesional de esta disciplina debe formular asesoramientos dirigidos a distintas poblaciones y contextos; coordinar trabajos en grupos de naturaleza interdisciplinaria. Estos requerimientos se convierten en un dato importante para la disciplina de la Orientación, cuyo propósito es poder evaluar si se están desarrollando estas competencias en la formación actual de las personas profesionales de la Orientación o bien poder anticipar e

Licencia Creative Commons

Atribución-No-Comercial SinDerivadas 
identificar las nuevas competencias profesionales que las instituciones o empresas empleadoras requieren de estos profesionales, para así, de esta manera, adaptar la formación su continua a esas necesidades.

Es interesante señalar como un hallazgo que, únicamente el $32 \%$ de las personas profesionales en Orientación encuestadas señalan el manejo de otro idioma como requerimiento de empleo que demanda esta profesión en la actualidad.

En relación con el segundo objetivo, el cual pretende identificar fenómenos sociales que pueden ser atendidos desde la disciplina de la Orientación, se identificaron en mayores porcentajes los siguientes: la violencia como vía para la solución de conflictos, el acoso escolar, el manejo inadecuado de las emociones, la drogadicción, las pocas competencias familiares para enfrentar retos actuales, la deserción escolar, una inadecuada educación de la sexualidad, estilos de vida no saludables, manejo inadecuado del estrés y el abuso infantil.

La Orientación, como práctica social, debe responder desde los ámbitos de su competencia a los fenómenos sociales que se presentan en la actualidad. Puede decirse que la sociedad actual demanda nuevos retos para la persona profesional de la Orientación. Como agente de cambio, debe ser capaz de identificar aquellas necesidades sociales que puedan ser abordadas desde esta disciplina. Es a través de la formación continua que buscará la transformación personal, organizacional y social.

El tercer objetivo pretende establecer necesidades de desarrollo profesional a través de la formación continua. Según el criterio de las personas graduadas de la licenciatura de la carrera de Orientación de la Universidad de Costa Rica y que ejercen la disciplina actualmente, se identificaron, en mayores porcentajes, las siguientes áreas que requieren mayor formación para enfrentar las demandas: el acoso escolar (bullying); procedimientos para hacer denuncias legales; legislación actual sobre asuntos pertinentes a sus labores; intervención en situación de crisis; identificación de indicadores conductuales de posibles trastornos de personalidad; intervención para personas y grupos en riesgo social; sexualidad humana; elaborar, aplicar e interpretar técnicas e instrumentos necesarios para la Orientación; informática y tecnologías aplicadas a la Orientación; derechos humanos; funciones cerebrales y neurodesarrollo, entre otros.

Esta información permite el cumplimiento del objetivo principal, el cual pretende establecer ejes y temáticas de interés de las personas graduadas de la carrera de Ciencias de la Educación con énfasis en Orientación de la Universidad de Costa Rica y satisfacer las necesidades de formación continua.

Situándonos en la información académica y laboral obtenida de las personas encuestadas, se puede apreciar que la mayoría de profesionales en Orientación laboran para el Ministerio de Educación Pública (MEP), siendo el Estado el mayor empleador, al amparo de la ley que lo sustenta.

A nivel estatal, se hace indispensable el apoyo de la gestión educativa, en función a sus competencias. Le corresponde a la administración entonces, promover la formación continua

Licencia Creative Commons

Atribución-No-Comercial SinDerivadas (cc) (†) 3.0 Costa Rica. 
del personal docente. Se le exige avanzar hacia nuevas formas y modelos de gestión, los cuales deben responder a las transformaciones sociales, políticas y económicas del país.

\section{Referencias}

Acuña, P., Carmiol, A., Elizondo, K., Salazar, M. y Villalobos, I. (2012). Elementos del sentido de vida desde un enfoque de resiliencia en cinco mujeres privadas de libertad que se encuentran en la etapa de adultez intermedia, en el Centro de Atención Institucional Calle Real - Liberia. (Memoria de Seminario de Graduación para optar por el grado de Licenciatura, Universidad de Costa Rica). Ciudad Rodrigo Facio, San José, Costa Rica.

Álvarez, V. y Romero, S. (2007). Formación basada en competencias para los profesionales de la Orientación. Educación XX1, 010, pp. 15-37. Recuperado de: http://www.redalyc.org/ articulo.oa?id=70601003

Arroyo, J. A. (2009). Gestión directiva del currículum. San José, Costa Rica: EUCR.

Barboza, A. y Gutiérrez, D. (2005). Técnicas e instrumentos de necesidades de formación docente. (VIII Congreso Nacional de Investigación Educativa, México). Recuperado de: http://www. upd.edu.mx/librospub/varios/TENECFOR.pdf

Bonals, J. y Sánchez, M. (2007). Manual de asesoramiento psicopedagógico. Barcelona: GRAÓ.

Castillero, A. B., Díaz, J. D., Morales, D. F. y Pino de Ocha, I. (2009). Gestión y supervisión en el centro de Educación Básica. Revista Colección Pedagógica Formación Inicial de Docentes Centroamericanos de la Educación Primaria o Básica, 36. San José, Costa Rica: CECC/SICA.

Calderón, K., Cruz, A., Castillo, C., Barquero, M. y Solano, A. (2010). La formación continua de docentes de Educación Inicial: Principales necesidades. (Seminario de Graduación para Licenciatura, Universidad de Costa Rica). Ciudad Rodrigo Facio, San José, Costa Rica.

Cobos, A. (2010). La construcción del perfil profesional de orientadora y de orientador. Estudio cualitativo basado en la opinión de sus protagonistas en Málaga. (Tesis doctoral, 
Universidad de Málaga). España. Recuperado de: http://www.biblioteca.uma.es/bbldoc/ tesisuma/17968501.pdf

De Mézerville, G. (2004). Ejes de salud mental. México: Trillas.

Escuela de Orientación y Educación Especial. (2000). Plan de estudio Bachillerato en ciencias de la educación con Énfasis en Orientación. Facultad de Educación, Universidad de Costa Rica. San José, Costa Rica: Sección de Orientación, Escuela de Orientación y Educación Especial.

Ferreres, V.e Imbernón, F. (1999). Formación y actualización para la función pedagógica. España: Síntesis.

García, J. L. (1999). Formación del profesorado. Necesidades y demandas. Barcelona, España: Praxis, S.A.

Herdonza, M. (s.f). Capacitación docente. Componet I Curriculum Development. Recuperado de: http://pdf.usaid.gov/pdf docs/PNACG311.pdf

Imbernón, F. (1994a). La formación y el desarrollo profesional del profesorado. Barcelona: GRAÓ.

Imbernón, F. (1994b). La formación del profesorado. Barcelona: Paidós.

Mata, A. (2003). La Orientación y el mejoramiento de la capacidad para el desempeño laboral del trabajador. Revista Actualidades en Orientación, 7, pp. 5-8. San José: Costa Rica: Asociación Costarricense de Profesionales en Orientación.

Mata, A. (2007). La investigación-acción para la formación continua de educadoras y educadores. San José, Costa Rica: INIE.

Mata, A. (2011). Una visión integradora de la Educación Continua. (Conferencia inaugural Red de Educación Continua de América Latina. 2011, XVI Encuentro Internacional, Universidad de Costa Rica). Ciudad Rodrigo Facio, San José, Costa Rica.

Pérez, A. y Blasco, P. (2003). Orientación e inserción profesional: Fundamentos y tendencias. Valencia, España: Guada Impresores S.L.

Licencia Creative Commons Atribución-No-Comercial SinDerivadas (cc) (†) 3.0 Costa Rica. 
Pozner, P., Ravela, P. y Fernández, T. (2000). Diez módulos destinados a los responsables de los procesos de la transformación educativa. Buenos Aires, Argentina: UNESCO-IIPE.

Tamayo y Tamayo, M. (2002). El proceso de la investigación científica. México: Limusa.

Sebastián, A. (2003). La orientación profesional. Un proceso a lo largo de la vida. España: Dykinson.

Uzcategui, R. (1990). Seguridad social. Venezuela: Academia Nacional de Ciencias Económicas.

Vargas, I. (2008). Percepciones sobre el desarrollo de la autoafirmación profesional en la formación inicial de profesionales en Orientación. (Tesis de Licenciatura, Universidad de Costa Rica). Ciudad Rodrigo Facio, San José, Costa Rica. 